\title{
Digital Preservation of a Famosa Fortress in Malaysia
}

\author{
Mohamad Izani, Alan Bridges, \\ Barnabas Calder, Michael Grant \\ Architecture Department \\ University of Strathclyde \\ 131 Rottenrow G4 ONG \\ +44 (0)1415483013
}

mohamad.zainal-abidin, a.h.bridges, p.m.grant, barnabas.calder@strath.ac.uk

\author{
Aishah Razak \\ Faculty of IT \\ University of Multimedia \\ Selangor, Malaysia \\ +44 (0)1418490477 \\ aishah@mmu.edu.my
}

\begin{abstract}
In this paper, we described an attempt to preserve the A Famosa Fortress in Malaysia in 3D model. First, a brief background of the A Famosa fortress is presented to justify the importance of preserving this historical heritage. Then the stages involved in the digital preservation process are discussed and some images of the 3D model of this fortress are illustrated. To evaluate the importance of the digital preservation of A Famosa and to find out its potential application in the tourism and education industry in Malaysia, a human evaluation has been conducted and the results are presented and discussed in detail.
\end{abstract}

\section{Categories and Subject Descriptors}

E.0 [General]; A.1 [Introductory and Survey]; I.6.5 [Model Development] - Modeling methodologies

\section{General Terms}

Documentation.

\section{Keywords}

3D model, digital preservation, historical heritage

\section{INTRODUCTION}

In the recent development, Melaka has been listed in the Unesco's world heritage list and Malaysia government have seriously put some efforts in preserving the old heritage of A Famosa fortress in Melaka. A large amount of money has been allocated for excavation and conservation work as an effort to preserve this historical relic. Within these few years, the conservation team had started reconstructing some of the discovered areas. Most of these areas are locations for the bastions. However, the work to uncover more of the buried wall, despite its historical significance and potential to draw more tourists into the area, may not be feasible as it would involve tearing up the major road that links the old town with the new commercial area, which has been reclaimed since the days of British occupation.

The site itself has been developed with the government and commercial buildings which would be very impractical and

Permission to make digital or hard copies of all or part of this work for personal or classroom use is granted without fee provided that copies are not made or distributed for profit or commercial advantage and that copies bear this notice and the full citation on the first page. To copy otherwise, or republish, to post on servers or to redistribute to lists, requires prior specific permission and/or a fee. eHeritage' 10 , October 25,2010 , Firenze, Italy.

Copyright 2010 ACM 978-1-4503-0156-5/10/10 $\$ 10.00$ expensive to uproot. Tracing the outline of the fort would mean uprooting the St Francis Xavier church built in 1849, the 250-year old Christ Church, Stadhuys - the old Dutch administrative buildings that were put up in 1650 , two police stations, corporate buildings and old shop houses, among others. With the complex logistic condition and geographical factor of the Melaka city today, it is impossible to fully reconstruct this fortress in its physical context. Considering all these factors, thus it is believed that rebuilding the fortress in $3 \mathrm{D}$ model is the most practical solution.

\subsection{A Brief Background of the Fortress}

Historically, the A Famosa Fortress is one of the oldest partially extant European buildings in Malaysia. Its origins may be traced back to the fortress built by the Portuguese in 1511. After Melaka fell into Portuguese, Albuquerque who was the captain for the new Portuguese government in Melaka had immediately ordered a fortress to be built for defensive purpose [1]. With this success, it also attracted the Dutch with the monopoly of the trading in South East Asia. The fortress of Melaka continued its architectural development over this time. Prior to the occupation of the Dutch, they heavily bombarded the fortress which had critically destroyed part of the fortress. After they succeeded to conquer Melaka in 1641, the Dutch carried out major reconstruction on the fortress as part of their strategy to strengthen their power. This reconstruction involved the extension of the fortress walls and bastions [2]. When the British took over the Dutch's position in 1795, the British captain in Melaka, William Farquhar instructed the fortress to be destroyed. As the result, the only evidence left today is a gate to access the fortress which is known as Porta de Santiago (Figure 1). The entire occupation timeline is summarised in the Table 1.

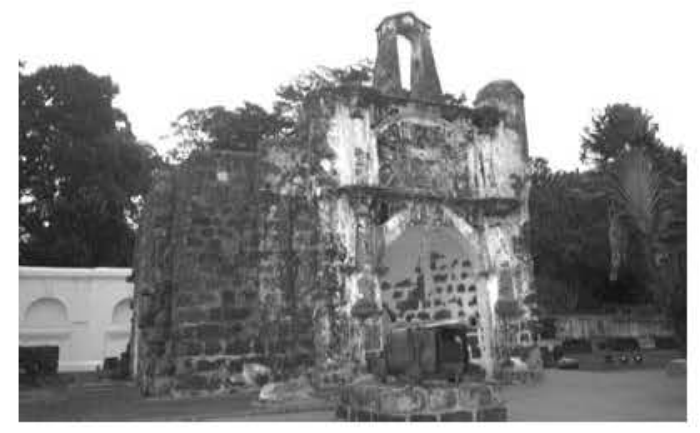

Figure 1. Remains of old Portuguese fortress, Porta de Santiago gate in Melaka 
Table 1: The timeline of occupation of A Famosa

\begin{tabular}{|l|l|}
\hline Conqueror & Occupation \\
\hline Portuguese & $1511-1641$ \\
\hline Dutch & $1641-1824$ \\
\hline British & $1824-1957$ \\
\hline
\end{tabular}

In 2003, the foundation of the Santiago bastion, part of the fortress wall was discovered during piling works for the Dataran Pahlawan Melaka Megamall project in Bandar Hilir. In November 2006, while the Melaka Government was building the 120 meters high "Melaka Tower" project just inside the heritage zone, besides the Melaka river, the piles of the tower hit something hard below the ground. Only upon excavation, the workers discovered the walls and foundations of another fortress bastion identified as Middleburgh. This new discovery was so important that the Ministry of Culture, Arts and Heritage has allocated more than RM 12 million to excavate and do research of this new founding. Finally, after years of excavation works, a bastion known as Middleburgh has been successfully reconstructed in 2009. Figure 2 shows the Middleburgh bastion which has been physically reconstructed.

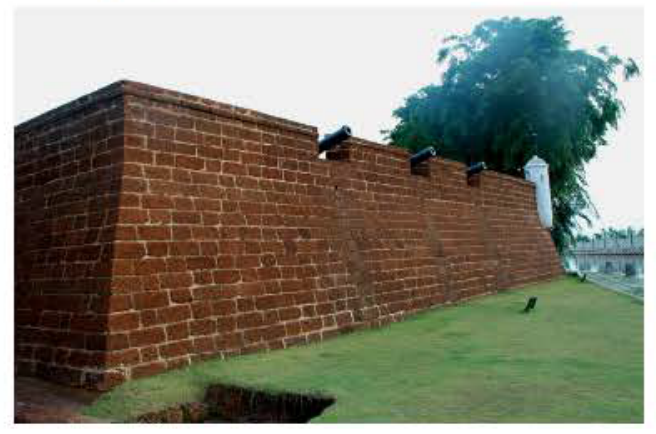

Figure 2. The Middleburgh bastion reconstructed by the excavation team

At the moment, the excavation team is working on reconstructing another bastion, known as Frederick Hendrick. However, due to feasibility and economic factors mentioned earlier, the project was currently suspended.

\section{PRESERVATION THE FORTRESS IN 3D}

Figure 3 shows the 3 stages involved in the process of preserving this fortress in 3D model:

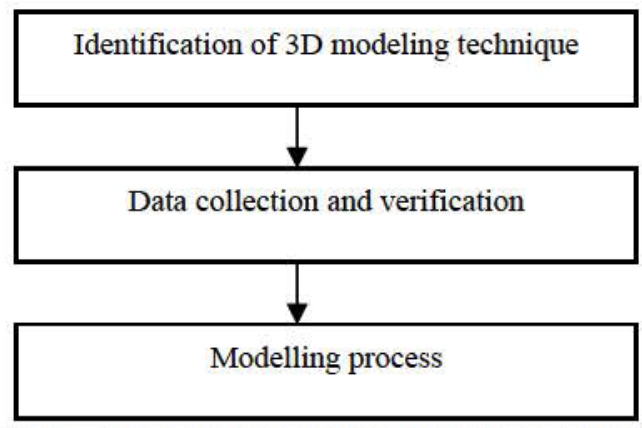

Figure 3. The 3 stages involved in the process of preserving this fortress in $\mathbf{3 D}$

\subsection{Identification of 3D modelling technique}

To identify the appropriate technique to be used, 3 projects which have similar situation have been selected and studied namely Michelsberg synagogue, The Jewish Quarter in Regensburg and Reconstruction of the old main church in Curitiba, Brazil. The result of the comparison shows that in general, the main similarities between A Famosa reconstruction and the three case studies are very limited resources and minimal physical remains of the building available. However in term of available data, Michelsberg synagogue and the old main church of Curitiba have some advantages over the A Famosa and Jewish Quarter in Regensburg since the buildings were still available until $19^{\text {th }}$ century. Thus, they have more reliable evidence such as photographs of the original buildings as compared to man made painting. The architectural drawings produced in this era are also more accurate and advance compared to the previous era. In case of A Famosa and Jewish Quarter in Regensburg, extensive data verification has to be done due to very old, inconsistent record and insufficient authoritative data.

Based on the findings, it is decided to use traditional 3D modelling technique to reconstruct the A Famosa fortress.

\subsection{Data collection and verification}

This stage is the most challenging and crucial part of this research. Since the 3D model of the fortress is to be constructed based entirely on the collected data, extensive data verifications have been conducted to verify the reliability and accuracy of the collected data. Some data verification techniques have been adopted such as mathematical verification using the rule of sine and cosine, image mapping using procrustes analysis, define and match technique through site visits to similar Portuguese and Dutch fortresses such as Fort Galle in Sri Lanka, Fort Rotterdam in Indonesia, Fort Aguada in India and also comparison of measurement between textual and visual data. Detail discussions on the techniques and analysis of the results have been presented in [3-5]. The summary of the verification processes involved in this stage is presented in Figure 4.

\subsection{Modelling process}

To accomplish the modelling process, 3D Studio Max software has been chosen for the entire process of $3 \mathrm{D}$ visualization such as polygonal modelling, texturing, lighting and rendering. The $3 \mathrm{D}$ modelling process is done in 2 stages which are; first modelling the fortress elements and then followed by the modelling of fortress wall.

In the first stage, the identified fortress elements gathered from previous stage are sketched into 3 views which are perspective view, internal wall view and external wall view. The sketches are done based on the findings gathered from the site visits mentioned in the previous stage. The sketches are then presented to some identified personal consisted of historian, leader of the conservation team and heritage body who are directly involved in the excavation and reconstruction of Middelburgh bastion for evaluation and feedback. Based on the feedback received, necessary modification and adjustment are made. The finalized sketches are then modelled into 3D. The process involved in this stage is summarized in Figure 5. 


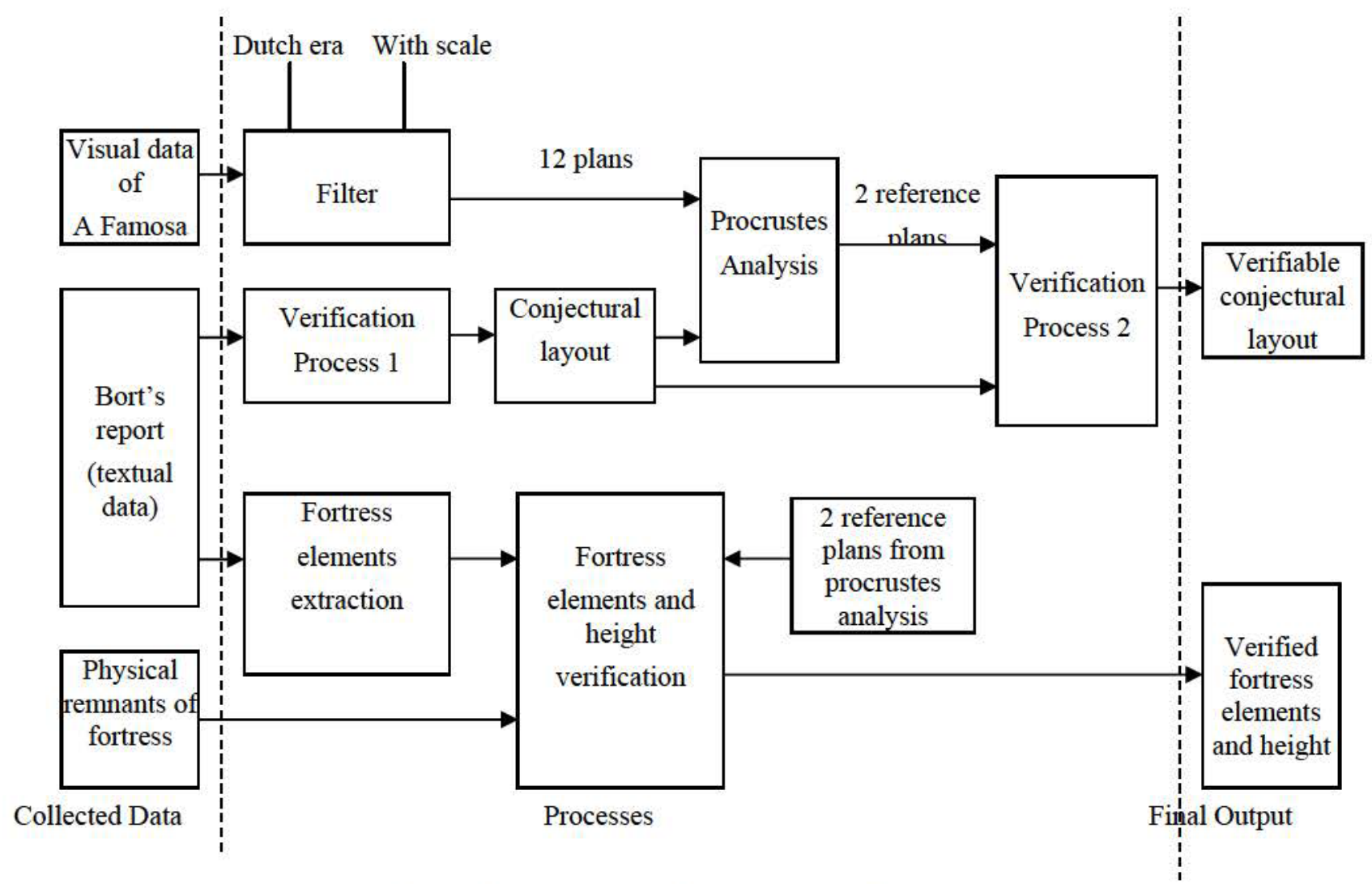

Figure 4. Summary of the data verification process

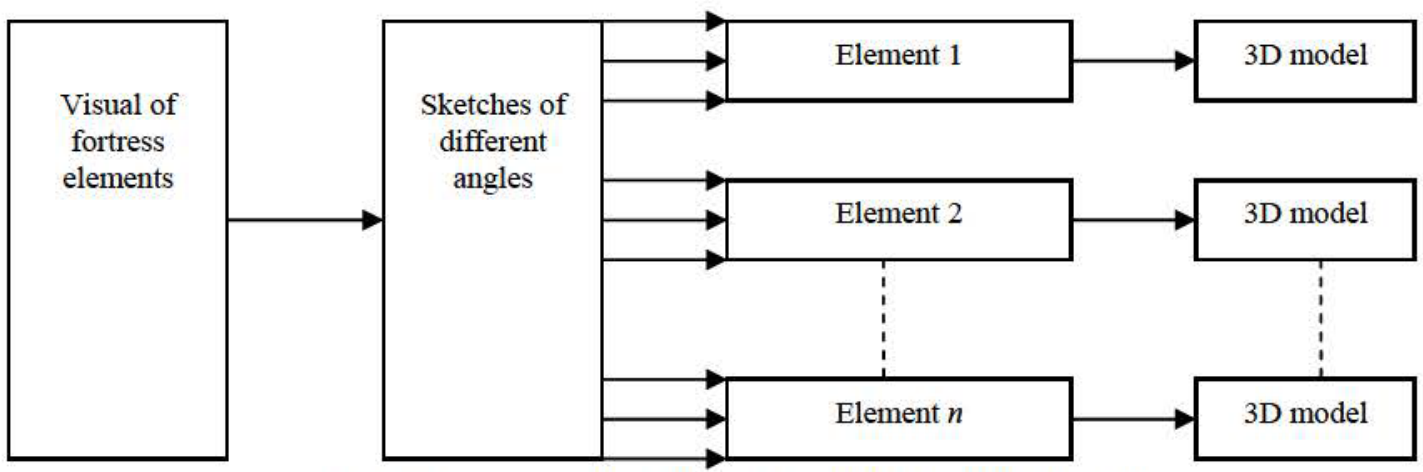

Figure 5.

The process of modelling fortress elements

The next stage is the modelling of the fortress wall which is summarized in Figure 6. To start the modelling process, the verified conjectural layout is mapped onto the satellite image taken from Google Earth. This is to match the location of the layout with the existing topology and mark the location of surviving existing building from the Portuguese and the Dutch era such as St. Paul church and Stadhuys. The information is then exported to line as shown in Figure 7 to be used in 3D Studio Max application. To complete the $3 \mathrm{D}$ visualization of this fortress, a mock up building models have been included inside the fortress. These buildings are not part of this research scope, however have been added for illustration purpose only. Figure 8 and 9 show the top and perspective view of the A Famosa in 3D Studio Max.

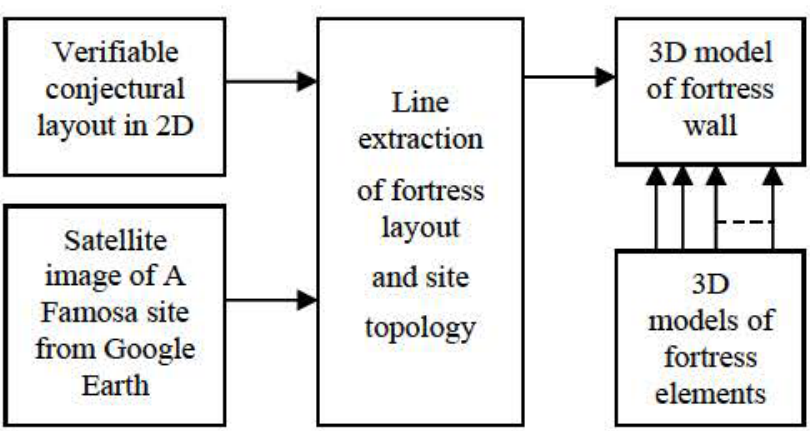

Figure 6. The process of modelling the fortress wall 


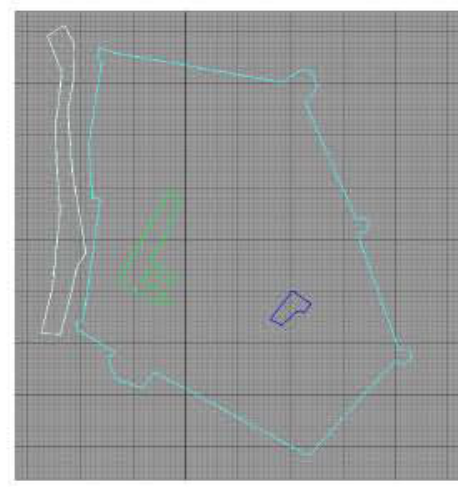

Figure 7. Extracted line from of the A Famosa layout

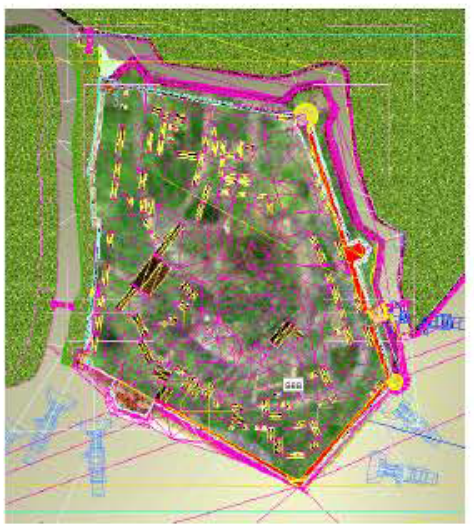

Figure 8. Top view of the 3D model of A Famosa in 3D Studio Max

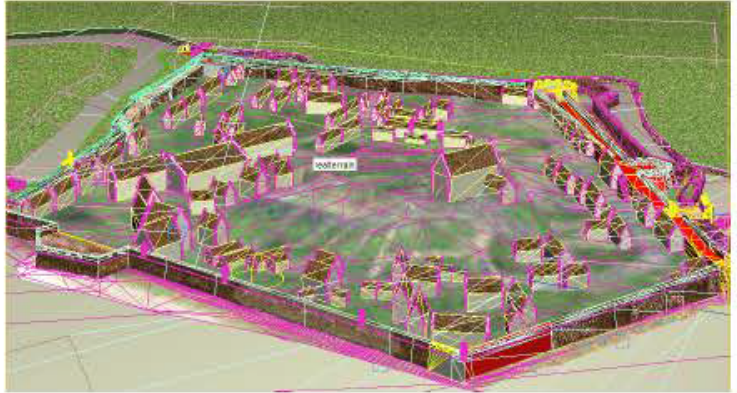

Figure 9. Perspective view of the 3D model of A Famosa in 3D Studio Max

\section{HUMAN EVALUATION}

This evaluation is conducted to gauge respondents' knowledge on A Famosa particularly before and after watching the 3D model and to identify the importance of digital preservation of A Famosa in $3 \mathrm{D}$. The result would justify the importance of further development of the 3D model applications to be used in fields such as tourism and education in Malaysia.

\subsection{Experimental set up}

This human evaluation has adopted subjective assessment where a total of 50 respondents have participated in the evaluation. The evaluation is divided into 2 sections. During the first section, a brief introduction on the project is presented to the respondents and followed by a pre-questionnaire to get some information on the respondents' initial knowledge of A Famosa and their initial opinion on the importance of A Famosa as a historical relic.

In the second section, a video presentation showing a brief history of A Famosa and the complete fortress in 3D model is presented to the respondent. This is followed by a post questionnaire to identify if there is any increase interest or knowledge on A Famosa compared to the previous questionnaire answers and also to get the respondent opinions and suggestions on the project. Figure 10 shows some snapshot of the video presentation on A Famosa in 3D model.
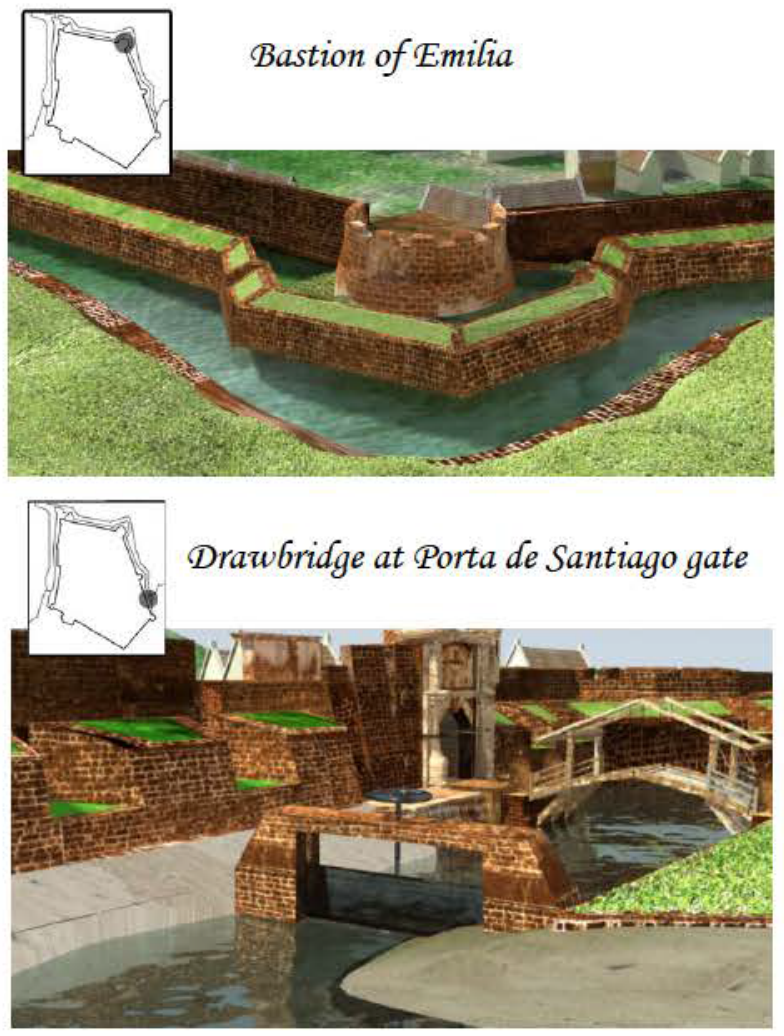

Figure 10. Some snapshots of the video presentation of $A$ Famosa in 3D

Initially, the evaluation is conducted manually by visiting selected academic institutions in Malaysia. The advantage of this approach is that beside the response from the survey, some interviews can also be conducted to get further response pertaining to the survey questions. However, to get more global response an online web survey using the same format has also being set up.

\subsection{Result and Analysis}

In the first part of the survey, it explored the background of the respondents. This information is important to ensure the reliability of the survey result. Since most of the survey ias conducted at selected academic institutions in Malaysia, majority of the respondent $(88 \%)$ consists of local people who are students and academicians. Another reason for choosing the respondents from academic line is because we intended to explore the possibilities of applying the $3 \mathrm{D}$ model in education. Another group of the respondents came from general worker (4\%) and professional 
(8\%). Among all the respondents, $86 \%$ are local people and $14 \%$ are foreigners.

The results of the survey are discussed in 5 points, namely:

- Knowledge on the history of Melaka and A Famosa

- The importance of A Famosa as a historical relic

- Suitable method for preservation: physical or 3D

- Feedback on the 3D model of Famosa presentation

- $\quad$ Suggestion for future works

The first 3 points are gathered from pre-questionnaire answers and the remaining two are from the post-questionnaire answers.

\subsubsection{Knowledge on the history of Melaka and $A$}

\section{Famosa}

When asked about the knowledge on the history of Melaka and A Famosa, $44 \%$ of the respondents have brief knowledge about A Famosa, $48 \%$ have a moderate knowledge and only $8 \%$ of the respondents knew thoroughly about the history. The result is shown in Figure 11. Further interviews with the respondents showed that the basic knowledge was gained from the history subject taught at school. The respondents who had better knowledge of A Famosa usually gained it from visiting the A Famosa site and some because they live in Melaka. Those who claim to have thorough knowledge are actually a historian or directly involved in the conservation project.

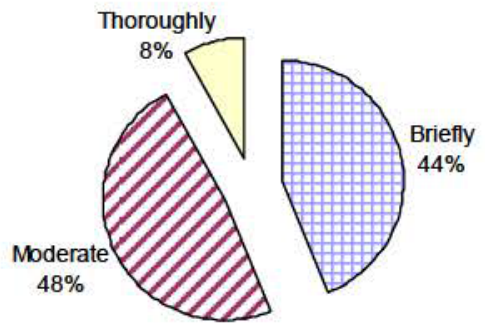

Figure 11. Pie Chart showing the respondents knowledge on the history of Melaka

Among the 50 respondents, $66 \%$ of the respondents had experienced being to the A Famosa site in Melaka while the remaining $34 \%$ had no experience at all. The main reason for not being able to visit A Famosa is mainly due to the distance factor such as living far from the site. The advantages of having the chance to visit the site are the opportunity to look at the remnants of the fortress and have some idea on the topology of the fortress site. Detail information on the fortress is also given at the fortress site such as the complete plan of the original fortress and some background history. Thus, the experience of being at the fortress site provided better understanding of how the fortress might actually looked like rather than just looking at the pictures of the fortress. This in turn will increase ones appreciation towards the heritage.

\subsubsection{The importance of A Famosa as a historical relic}

Figure 12 shows the response on the importance of A Famosa as a historical relic. Although majority of the respondent $(66 \%)$ strongly agreed that A Famosa is an important historical relic, around $26 \%$ doubted about it and $8 \%$ felt that it is not very important. Further interviews with these 2 groups indicated that their response is due to the lack of knowledge on the history of A Famosa. Some of them have viewed A Famosa as just a gate as presented by the Santiago gate thus they failed to recognise the importance of this relic.

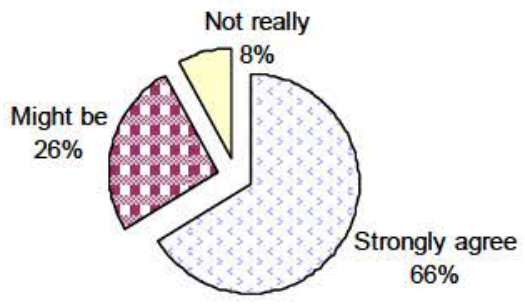

Figure 12. Pie Chart showing the respondents opinion on the importance of $\mathbf{A}$ Famosa as a historical relic

\subsubsection{Suitable method for preservation: physical}

reconstruction or $3 D$

About $60 \%$ of the respondents think that A Famosa fortress should be physically preserved to its original state for historical purpose, even though it might be very expensive and involve a lot of reconstruction work at the original site. However, $28 \%$ think that other alternative such as digital preservation in $3 \mathrm{D}$ model should be considered taking into account the cost and feasibility factors of rebuilding the fortress to its original form. Another $12 \%$ failed to see the importance of preserving this fortress in any form. This finding is shown in Figure 13.

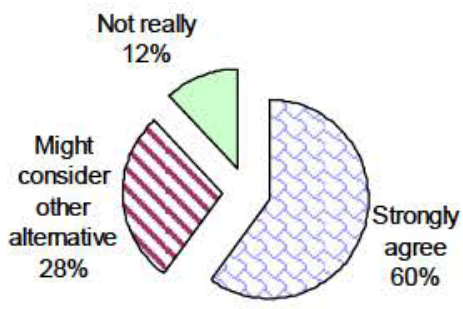

Figure 13. Pie Chart showing the respondents opinion on the importance of physical reconstruction of A Famosa

\subsubsection{Feedback on the 3D model of Famosa presentation}

When asked about the first impression after watching the $3 \mathrm{D}$ model of A Famosa presentation, $36 \%$ of the respondents said that they were impressed, $30 \%$ felt that the presentation was knowledgeable, $24 \%$ said the video made them appreciate the fortress more, $4 \%$ felt proud and $6 \%$ have other mixed feelings such as surprised and undefined. The result is shown in Figure 14. 


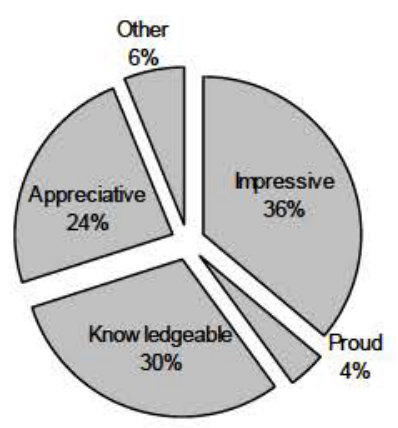

Figure 14. Pie Chart showing the respondents first impression after watching the 3D model of A Famosa presentation

Figure 15 shows significance increase on the respondent's perception on the importance of A Famosa as a historical relic after viewing the presentation as compared to the earlier result shown in Figure 12. This finding has shown that presenting the complete fortress in 3D model can give the viewer a clearer idea on the A Famosa fortress and in return improve their knowledge and appreciation on the historical heritage.

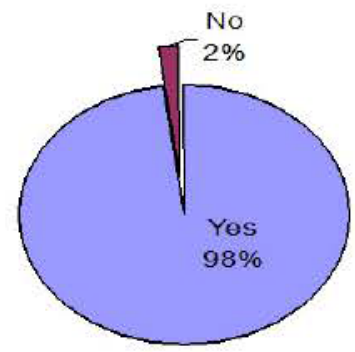

Figure 15. Pie Chart showing the respondents opinion on the importance of A Famosa as a historical relic after watching the $3 \mathrm{D}$ model of $\mathrm{A}$ Famosa presentation

\subsubsection{Suggestion for future works}

Overall the survey received good feedbacks and several suggestions have been suggested by the respondent to make the presentation more interesting for tourism and education:

i- $\quad$ To include more interactivity in the presentation such as the ability to have virtual tour around the fortress.

ii- To make the content more interesting by adding $3 \mathrm{D}$ characters, plants and more realistic environment for more effective impact to the audience particularly in creating realistic experience.

iii- To use more advance application such as Virtual Reality (VR) and 3D game engine.

\section{CONCLUSIONS AND FUTURE WORKS}

In this paper, we discussed the stages involved in the digital preservation of A Famosa Fortress in Malaysia. A survey has been conducted to gauge respondents' feedback on this attempt and find out their opinion on the importance of preserving this historical relic. In general, the findings have shown that people would appreciate the importance of a historical relic when they are more knowledgeable of the subject matter. Even though many would think that physical preservation would be the most appropriate to experience the history, but after looking at the output of this project the respondents agreed that preserving in 3D not only can overcome the economic and feasibility problem of physical reconstruction, but also has overcome the need to travel to a certain location in order to appreciate a particular relic. A significant increase on the importance of A Famosa as a historical heritage can be seen in the respondent's feedback after watching the $3 \mathrm{D}$ model of this fortress which implied that digital preservation can increase knowledge and people's interest on a particular historical heritage.

For future work we plan to expand the contents development of this research into more practical application such as virtual reality and virtual walkthrough using game engine. We intend to explore on the use of VR technology to help quantitatively and qualitatively expand, deepen and enhance the architectural educational experience through its functions as an instrument of historic learning, animation, and reconstruction of past architectural and urban planning legacies.

\section{ACKNOWLEDGMENTS}

Our thanks to British Council for sponsoring this research under Prime Minister 2 Initiative grant.

\section{REFERENCES}

[1] Godinho de Eredia, M., \& Mills, J. V. 1997. Eredia's description of Malaca, Meridional India, and Cathay. Kuala Lumpur, Malaysia: Malaysian Branch of the Royal Asiatic Society.

[2] Leupe, P. A. \& Hacobian, M. 1936. The siege and capture of Malacca from the Portuguese in 1640-1641. In Journal of the Malayan Branch of the Royal Asiatic Society, ( 14 (1), 1936, pp. 1-178)

[3] Izani, M., Bridges, A. \& Razak, A. 2009. Determination of the plan of the A Famosa Fortress, Malaysia. In Proceeding of International Conference on Computing and Informatics (Kuala Lumpur, Malaysia ,June 2009). ICOCI09

[4] Izani, M., Bridges, A. \& Razak, A. 2009. Using procrustes analysis to determine verifiable conjectural layout of A Famosa fortress, Malaysia. In Proceeding of International Conference on Software Technology and Engineering (Chennai,India July 2009). ICSTE09.

[5] Izani, M., Bridges, A. \& Razak, A. 2009. 3D Modeling of A Famosa Fortress, Malaysia based on comparison of textual and visual data. In Proceedings of 6th International Conference Computer Graphics, Imaging and Visualization (Tianjin, China, August 2009).CGIV 09. 